\title{
Value Systems Management Model for Co-innovation
}

\author{
Patrícia Macedo ${ }^{1,2}$ and Luis M. Camarinha-Matos ${ }^{1}$ \\ ${ }^{1}$ Faculty of Sciences and Technology, Universidade Nova de Lisboa, Portugal \\ ${ }^{2}$ Polytechnic Institute of Setubal, Portugal \\ pmacedo@est.ips.pt, cam@uninova.pt
}

\begin{abstract}
Nowadays innovation and collaboration are strategic issues for enterprises to remain competitive in the global market. Many new developments are carried out with external partners, including universities and research institutions aiming to generate novel solutions in order to improve business performance and sustainability. However, the balance between intellectual property protection and intellectual property sharing is hard to manage. In order to increase the sustainability of innovation networks it is important to provide mechanisms to easily define the profile of the collaboration and to assess the degree of alignment with the potential partners. This paper aims to discuss how these mechanisms can be provided through the implementation of a Core Value Management System in the scope of co-innovation.
\end{abstract}

Keywords: collaborative networks, value systems, intellectual property, co-innovation.

\section{Introduction}

Nowadays, the strive to achieve innovation correspond to a very costly and risky process, being difficult for companies to innovate in short periods of time in a global market, where customers' needs change quickly and the products/services' life cycles get shorter. This is a particular tough challenge for small and medium enterprises (SMEs). Therefore, many new developments are carried out with external partners, including universities and research institutions with the aim to improve business performance and its sustainability, as well as to reduce risks.

Co-innovation is a new business paradigm where it is assumed that firms or individual persons can establish a partnership with the aim of jointly developing new ideas and new products [1]. These kinds of partnerships raise new challenges in the scope of trust management and intellectual property management $[2,3]$, since the balance between intellectual property sharing and intellectual property protection is hard to manage. Moreover, if partners have different perceptions of outcomes and different notions of the expected behavior, this might, in some cases, lead to some behaviors that compromise collaboration sustainability. For instance, if a firm does not believe in the importance of sharing knowledge, then it can be expected that its behavior will not contribute positively to the development and implementation of new ideas or new technologies in alliance with other firms.

Since a Value System defines the set of values and priorities that regulate the behavior of an organization, it determines or at least constrains the decision-making 
processes of that organization. Therefore, the identification and characterization of the Value Systems of the network and its members is fundamental when attempting to improve collaboration [4]. Consequently it is important to develop mechanisms to facilitate the definition of the profile of the co-innovation partnership in terms of values. Moreover, it is also relevant to develop mechanism to assess the degree of alignment between the values required for the partnership and the values hold by the potential partners.

The research performed aimed to address the following question: What would be an adequate modeling framework for supporting effectively the specification and analysis of Value System in collaborative environments?

Even so, this paper presents only part of the results achieved during this research, more specifically, it discusses how the models and methods proposed in [5-7] can be applied to analyze and assess the level of alignment between the network and the potential partners in terms of collaborative innovation profile.

\section{Contributions to Sustainability}

The development of new products and services in a short period of time is a key condition to survive in the global market, however this represents also a big challenge for small and medium enterprises. The co-innovation paradigm brings a new way to conduct innovation, being focused on the cooperation with others to achieve innovations. In order to support this paradigm it is important to provide mechanisms to effortlessly define the values profile required for the innovation network and to assess the degree of values alignment between it and its potential partners. This paper aims at contributing to sustainability under the economic perspective in the way that it proposes mechanisms to deal with some of the challenges of co-innovation, thus leading to better survival of SMEs in turbulent market conditions.

\section{Related Work on Value Systems Management}

Early Value Systems management studies have been conducted essentially in social sciences, where scientists have discussed the importance of values management for the success of organizations and the importance of values alignment. For instance, Rokeach and Schwartz [8, 9] developed some empirical methods to identify core-values. Based on this work they proposed organizational core-values taxonomies. From the economic field perspective, the Value System concept has been developed based on the assumption that value means how much (usually money) a product or service is worth to someone. This notion has been introduced by Porter [10], that considered that Value System management comprises the management of the set of activity links where there is value creation, such as the links among a firm and its suppliers, other businesses within the firm's corporate family, distribution channels and the firm's end-user customers. This notion has been extended by Alle [11] towards supporting a wider notion of value under which the term is associated to "anything that can give rise to exchange", leading to the Value Network Model. In recent years some studies have explored the importance of Value Systems in the context of Collaborative Networks (CN) [4, 12, 13]. Furthermore, a set of tools (frameworks, methods and a 
web application) $[6,7]$ have been proposed based on a Value System Conceptual Model to support the configuration and analysis of Value Systems in collaborative environments. However, such set of tools have just been applied to $\mathrm{CNs}$ in general terms, none of them being applied to support co-innovation management in particular.

\section{Core Value System Management Model}

In previous works, we have proposed a conceptual model for Value Systems [5] in an attempt to provide a unified definition of the concept that embraces not only the notion accepted in Sociology, but also the notions developed in the Economy and Knowledge Management fields for Value Systems.

A Value represents the relative
importance of an entity, for a given
evaluator.
A Core-value is a main characteristic of
the organization (or CN) that motivates
and regulate its behavior.
A Value System is defined by the set of
things (resources, processes,
behaviours, relantionships, beliefs,
information) that can be evaluated and
that are important to the evaluator, as
well as, the respective mechanims of
their evaluation.
A Core Value System is a specialization
of Value System, that assumes the
organization or the CN as the object of
evaluation, and the core-values as the
set of characteristics to be evaluated.

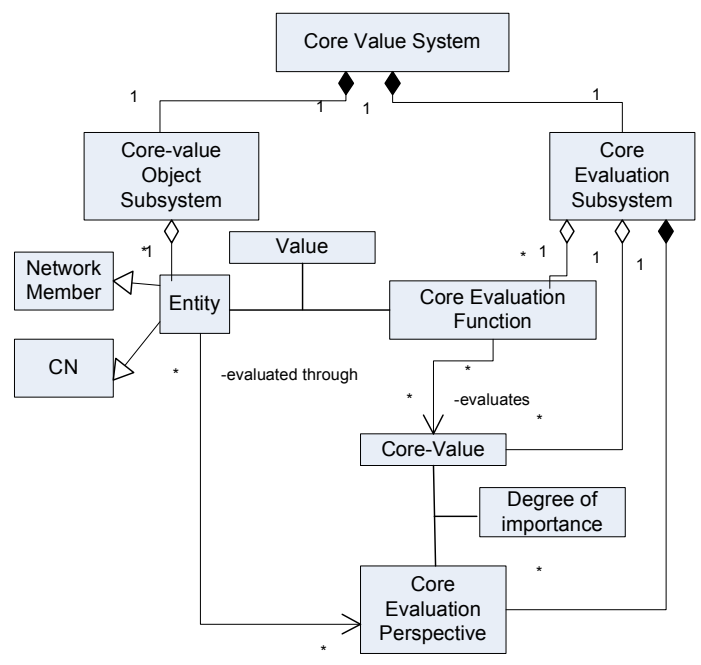

Fig. 1. UML Diagram of the CVS Conceptual Model

The set of characteristics that each organization (or network of organisations) considers as the most important for itself and that motivate or regulate its behavior are called core-values. Departing from the notion of core-values we have introduced a conceptual model for Core Value System (CVS) [6], that encompasses the core-values notion. This concept is a restricted view of the generic Value System model of which it can be considered a specialisation. The UML class diagram presented in Fig. 1 illustrates the structure of the CVS model. Accordingly, a CVS is composed of two subsystems: (i) the core-value objects subsystem, which is represented by the organization or networked organization itself; (ii) the core evaluation subsystem, which represents the elements of evaluation, such as the core-values, the core-evaluation perspective and the functions to evaluate the organization's core-values. The set of core-values of an actor and respective preferences (degree of importance) are represented according to the CVS conceptual model by the core-evaluation perspective, which becomes the main structural element in the proposed approach. 


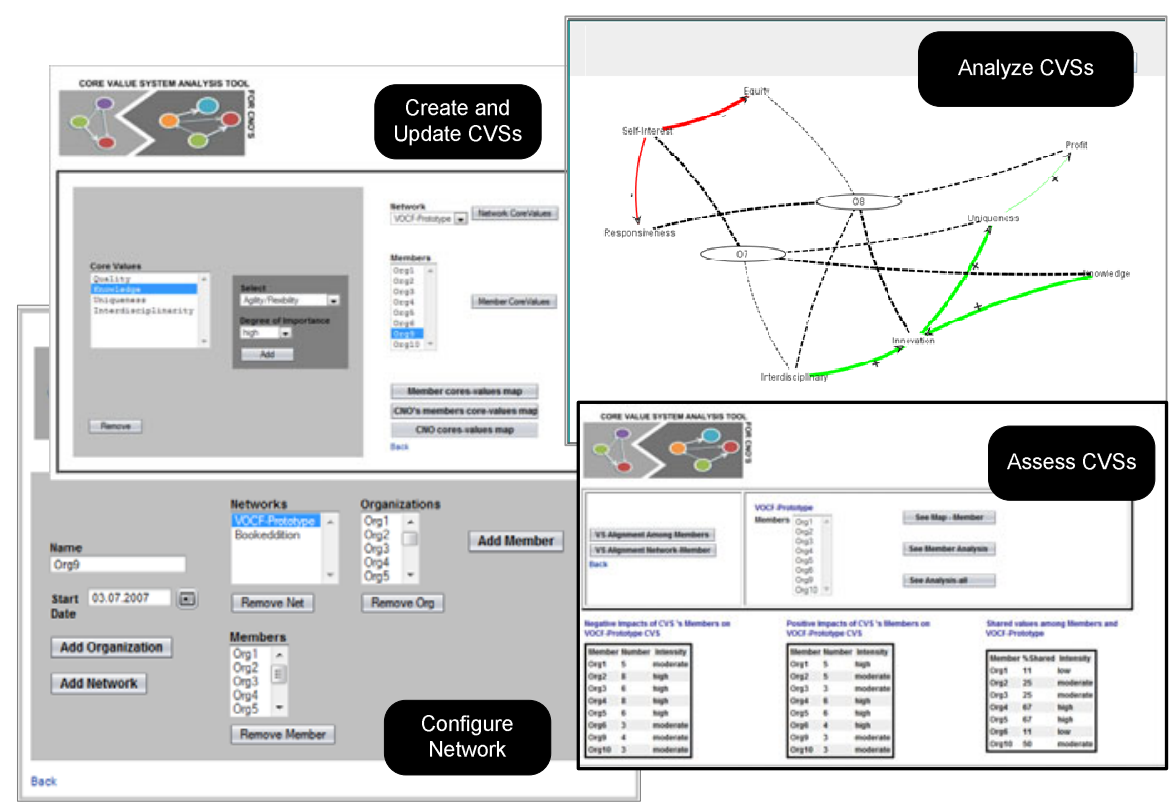

Fig. 2. Web-based tool to support CVSs Management

Aiming to provide methods to systematically analyze CVSs in collaborative environments, we have also proposed a set of qualitative reasoning methods [7] supported in a framework of analysis based on qualitative causal maps and graphs. The construction of three elementary maps is proposed in this framework.

1. Core-values influence map: Use of causal maps to show how core-values influence positively or negatively each other, and the intensity of the influence.

2. Organizations' core-values map: Use of graphs to show the core-values held by each organization and its degree of importance, as well as the core-values shared by organizations.

3. CN's core-values map: Use of graphs to show the core-values held by the $\mathrm{CN}$ and their degree of importance.

Departing from these elementary maps, it is possible to aggregate them in order to build maps that evidence the impact of one CVS onto another [6], facilitating the analysis process. Analysis is one of the components of the CVS management process, which includes the following activities:

- Create: CVS are configured. For each CVS, the core-evaluation perspectives have to be defined for the network and for each member.

- Update: CVS can be modified. As priorities can change during long-term collaboration activities, there is the need to adjust the degree of importance of the core-values.

- $\quad$ Analyse: The created CVS has to be examined in detail, in order to understand which core-values are shared with other partners, and which core-values influence positively or negatively other CVSs. This analysis should cover the network 
level and the member level. At the network level is analyzed the network CVSs and the impact of the members' CVSs on the network's CVS are analyzed, while at the member level the CVS of each member and the interaction among members' CVSs are analyze.

- Assess: A comparative assessment can be made, where the level of fitness between two CVSs is assessed using distinct criteria. This assessment can also cover the network level and the member level, considering in each case the degree of importance of the core-values to infer the level of CVSs alignment.

A web-based tool to support the CVS management was developed (see Fig. 2). Essentially, the CVSs alignment analysis can be performed among network members' CVSs, or between the network's CVS and the CVS of a partner or a potential partner. The tool is divided into four functional components: (i) Core-values knowledge management - to be used by the knowledge experts in order to specify core-values and their characteristics; (ii) Core Value System Configuration - to be used by brokers, network managers or network members in order to define their CVSs; (iii) Core Value Systems Analysis - to be used by brokers, network managers and network members in order to analyze their CVS; (iv) Access management tool - provides features that allow the tool manager to configure accesses to the tool according to the user profiles.

\section{Applying Value System Management to Support Co-Innovation}

Theoretical considerations: The alliances established with the aim of developing new products and new technologies should have specific characteristic. Chesbrough [3] defends that for firms to be able to successfully implement the co-innovation business model, they have to be capable of sharing their knowledge, being flexible and being responsive. However, Flores et al. [2] defend another set of characteristics as being the most important ones for working in an co-innovation business model. Although there is no unique set of common characteristics accepted by the researchers, it is acknowledged that the set of core-values taken by each firm, determine their behaviour in the collaboration process of creation. Therefore, the definition of the set of characteristics required to work in a sustainable way in an innovation network, can be an important step for the sustainability of these networks. As such, the collaborative innovation evaluation perspective will represent this set of required characteristics. The collaborative innovation evaluation is in fact, an instantiation of a core-evaluation perspective, and is defined as: $p e_{\text {co-innovation }}=\{\langle d v, w v\rangle\}$, where:

- $\quad d v$ is the vector of core-values considered as relevant for the co-innovation process. $d v=\left[c v_{1}, c v_{2}, \ldots . c v_{n}\right]: c v_{i} \in C V$

- $\quad w v$ represents the weights-vector, where each element defines the degree of importance of the corresponding core-value. These preferences can be expressed qualitatively.

As previously proposed in [6] and [7], not just the common core-values will be considered as relevant criteria to assess the values alignment between two entities, but also the core-values that influence positively or negatively the core-values specified in the collaborative innovation evaluation perspective will be considered. Thus, the notion 
of collaborative innovation value profile is introduced to cover this idea. The collaboration innovation value profile of a partner shows which of its core-values are aligned and which are misaligned with the collaborative innovation characteristics required for the partnership. That is indeed, all the core-values belonging to the partner's CVS that meet one of the following criteria:

- $\quad$ the core-value belongs to the collaborative innovation evaluation perspective.

- the core-value has a positive influence on a core-value belonging to the collaborative innovation evaluation perspective.

- the core-value has a negative influence on a core-value belonging to the collaborative innovation evaluation perspective.

The use of the mentioned set of maps based on causal maps and graph theory in the context of the innovation network, will allow us to easily identify the core-values that compose the collaboration innovation value profile of each network member. The three alignment indicators proposed to assess values alignment [7]: (i) Shared Values Level; (ii) Positive Impact Level; (iii) Potential for conflict level, may be applied to calculate the Collaborative Innovation Values Profile using just minor adjustments, such as:

- A collaborative innovation evaluation perspective has to be configured in the CVS of the innovation network.

- A core-evaluation perspective has to be configured in the CVS of each potential partner.

- $\quad$ Through the observation of the complete aggregate maps generated for the innovation network, the core-values belonging to each Collaborative Innovation Values Profile are identified.

- $\quad$ The Shared Values Level, the Positive Impact Level, and the Potential for conflict level between the network and each partner are calculated, obtaining the level of each core-value in the profile.

The example below illustrates how these concepts can be applied.

Illustrative example: This example intends to illustrate how to apply the Value System Management Model in order to assess the Collaborative Innovation Values Profile Alignment. The data used in this example was obtained through a survey conducted in the scope of a case study done inside the ECOLEAD project [14]. Hence, this example cannot be considered as a full case study, but as a potential application where the scenario and the data used are both real.

The ECOLEAD project was divided into several work packages. Each work package team was created to respond to a specific set of objectives. For this illustrative example the development of some components of the VO Creation Framework (VOCF) prototype is considered. The development of this task can be considered as a co-innovation process, since it comprises the collaborative development of an innovative product carried out by a heterogeneous group of organizations. For this group the following collaborative innovation evaluation perspective was specified:

$$
\begin{aligned}
& p e_{\text {co-innovation }}<d v_{l}, w v_{l}> \\
& d v_{l}=[\text { Innovation, Knowledge Sharing, Agility, Responsiveness] } \\
& w v_{l}=\text { [high, very high, high, very high]. }
\end{aligned}
$$


Two Universities, one Research Institute of Applied research, and one SME Network joined the group (for a question of privacy, the partners are not identified). For these four organizations the work package manager has provided the data required for specifying the following core-evaluation perspectives:

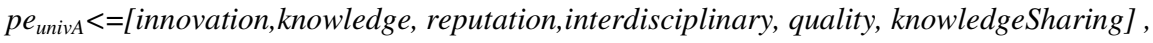

[very_high, very_high, fair, fair, high, high]>

$p e_{\text {univ }}<=<=$ [innovation, knowledge, reputation, interdisciplinary, reliability, knowledgeShar-

ing], [very_high, very_high, fair, high, high, high]>

pe researchlnstitute $==[$ Innovation, Uniqueness, Self-Interest, Interdisciplinary ], [high, very_high ,fair, high] >

pe SMEnetwork $<=[$ Profit, FinancialStability, Responsiveness, Agility,], [very_high, very_high, very_high,fair] >

Table 1. Core-values Alignment Assessment Results

\begin{tabular}{|c|l|l|l|}
\cline { 2 - 4 } \multicolumn{1}{c|}{} & \multicolumn{1}{c|}{$\begin{array}{c}\text { Shared Values } \\
\text { Level }\end{array}$} & \multicolumn{1}{c|}{$\begin{array}{c}\text { Positive } \\
\text { Impact Level }\end{array}$} & $\begin{array}{c}\text { Negative } \\
\text { Impact Level }\end{array}$ \\
\hline UnivA & Moderate & High & None \\
\hline UnivB & Moderate & Moderate & None \\
\hline Research Institute(RI) & Low & Low & High \\
\hline SME Network & Low & Moderate & None \\
\hline
\end{tabular}

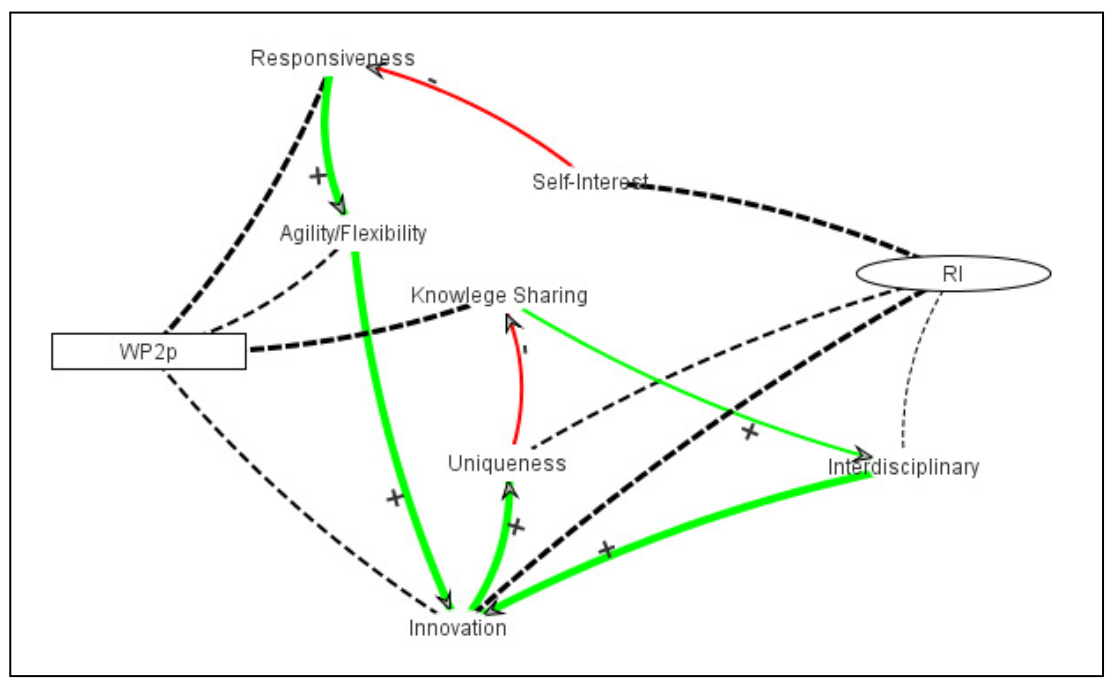

Fig. 3. Complete Aggregate Map for Research Center

Applying the qualitative assessment inference methods (described in detail in [7]) to evaluate the degree of alignment in terms of co-innovation characteristics of each innovation partner, the results presented in Table 1 can be achieved. Observing these results, it can be noticed that the Research Institute is not aligned with the Innovation Group's collaborative innovation evaluation perspective. 
Furthermore, if we determine the collaborative innovation values profile (see Table 2) for each potential partner, we realize that group manager should pay special attention to the Research Institute behavior, since it presents some risk. This risk comes due to the fact that it defends Uniqueness (being unique) as an important characteristic, and the Uniqueness core-value has a negative influence on Knowledge Sharing, which is a core-value belonging to the collaborative innovation evaluation perspective, as it is illustrated in the complete aggregate core-values map presented in Fig. 3. Moreover, since this Research Institute is also characterized for acting according to its own interests (Self-interest), it is expected that it often does not be as responsive (Responsiveness) as required.

Table 2. Collaborative Innovation Values Profile

\begin{tabular}{|c|c|c|c|c|}
\hline & Shared Values & $\begin{array}{l}\text { Positive } \\
\text { Impact }\end{array}$ & $\begin{array}{l}\text { Negative } \\
\text { Impact }\end{array}$ & $\begin{array}{c}\text { Innovation } \\
\text { Collaborative } \\
\text { profile }\end{array}$ \\
\hline 郎 & $\begin{array}{l}\text { (innovation,high), } \\
\text { (knowledgeSharing,very_high) }\end{array}$ & $\begin{array}{l}\text { (innovation,strong), } \\
\text { (flexibility,strong) }\end{array}$ & & \begin{tabular}{|l} 
(innovation,very_high), \\
(knowledgeSharing,very_high) \\
(flexibility, high)
\end{tabular} \\
\hline ص & \begin{tabular}{|l} 
(innovation,high), \\
(knowledgeSharing,very_high)
\end{tabular} & (knowledgeSharing,moderate) & & \begin{tabular}{|l} 
(innovation,high), \\
(knowledgeShar- \\
ing,very_high)
\end{tabular} \\
\hline 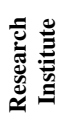 & (innovation,high) & & $\begin{array}{l}\text { (uniqueness, high) } \\
\text { (self - interest, moderate) }\end{array}$ & \begin{tabular}{|l} 
(innovation,high), \\
(uniqueness, negative-high) \\
(self - interest, moderate)
\end{tabular} \\
\hline 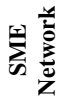 & $\begin{array}{l}\text { (agility,high), } \\
\text { (responsiveness,very_high) }\end{array}$ & (responsiveness,moderate) & & $\begin{array}{l}\text { (agility,high), (responsive- } \\
\text { ness,very_high) }\end{array}$ \\
\hline
\end{tabular}

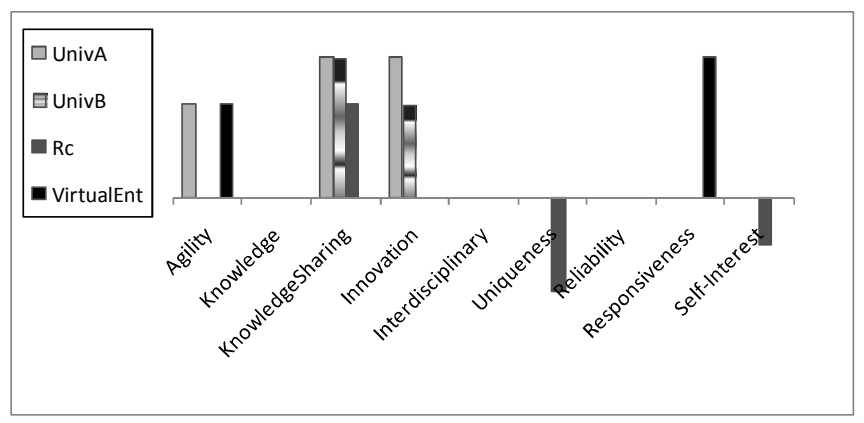

Fig. 4. Innovation Collaborative Values Profiles represented by a bar chart

Picking up the results presented in Table 2 a bar chart can be drawn (see Fig. 4) to visually illustrate the collaborative innovation values profile for each partner in the scope of this specific innovation opportunity. This chart evidences that the Research Institute 's collaborative innovation values profile has a negative impact on the collaboration opportunity. Moreover, we can easily notice that Knowledge Sharing is a relevant characteristic that contributes to the sustainability of this collaboration 
relationship. Responsiveness, Agility and Innovation are also core-values that contribute positively to be aligned with the collaborative innovation values specified for this co-innovation opportunity.

\section{Validation Process}

The constructive research method [15] was the methodology selected to guide this research process. Following the constructive approach, a concept introduced through previous research can be applied to solve a specific problem, usually through the development of an artifact or a set of artifacts (models, diagrams, frameworks). March and Smith [16] claim that in this case, "the research contribution lies in the novelty of the artifact and in the persuasiveness of the claims that it is effective. Therefore, in order to validate the subsequent solution, two points have to be demonstrated: (i) that the artifact or set of artifacts proposed solve the domain problem and/or create knowledge about how the problem can be solved; (ii) how the solution proposed is new or better than previous ones.

The proposed Value System Management Model shows, to some extent, how it creates knowledge about how the problem can be solved. Moreover, the example presented above shows how the proposed approach solves the domain problem. The consistency of the CVS management model can be claimed, in view of the fact that it applies a set of models and methods previously verified and validated. Additionally, the novelty of the proposed approach can be claimed, because it was a first attempt to apply a Value System Management Model to manage value profiles in order to identify partners that are more adequate to collaborate in innovation process. However, the process of collecting evidences that allow us to claim the general usefulness of the design models and proposed method have to proceed. Thus, the development of a complete case study in the scope of the innovation networks is a future priority step towards that goal.

\section{Conclusions and Future Work}

This paper discussed how the implementation of a Core Value Management System can be useful for the establishment and sustainability of partnerships created following the co-innovation paradigm. Departing from a set of previously proposed tools, to specify and analyse Core Value Systems in collaborative environments, it has been described how they can be configured to determine collaborative innovation values profiles; and to assess if a potential partner has a values profile that is aligned with the partnership in terms of the core-values needed to work in such innovation network.

This approach has the following advantages: (i) it facilitates the representation of knowledge about the relevant core-values to the partnership in terms of innovation; (ii)it increases the "transparency" about the decision-making processes in the partner selection; (iii) it provides a visual representation of the interaction among partners in terms of core-values, allowing a better communication with the stakeholders.

Despite the work done so far suggests that the artefacts presented have a practical and theoretical relevance, the validation process for its complexity, has not yet been completed. Thus, the implementation of the CVS management model in a co-innovation network will be the next step. 
Acknowledgements. This work was supported in part by the Portuguese "Fundação para a Ciência e a Tecnologia" (Portuguese Foundation for Science and Technology) through a PhD. scholarship.

\section{References}

1. Gloor, P.: Swarm creativity: competitive advantage through collaborative innovation networks. Oxford University Press, USA (2006)

2. Flores, M., Al-Ashaab, A., Magyar, A.: A Balanced Scorecard for Open Innovation: Measuring the Impact of Industry-University Collaboration. In: Camarinha-Matos, L.M., Paraskakis, I., Afsarmanesh, H. (eds.) PRO-VE 2009. IFIP AICT, vol. 307, pp. 23-32. Springer, Heidelberg (2009)

3. Chesbrough, H.: The era of open innovation. Managing innovation and change 127 (2006)

4. Macedo, P., Sapateiro, C., Filipe, J.: Distinct Approaches to Value Systems in Collaborative Networks Environments. In: Camarinha-Matos, L., Afsarmanesh, H., Ollus, M. (eds.) Network-Centric Collaboration and Supporting Frameworks, vol. 224, pp. 111120. Springer, Boston (2006)

5. Camarinha-Matos, L.M., Macedo, P.: A conceptual model of value systems in collaborative networks. Journal of Intelligent Manufacturing, 1-13 (2008)

6. Macedo, P., Abreu, A., Camarinha-Matos, L.M.: A method to analyse the alignment of core values in collaborative networked organisations. Production Planning \& Control 21, 145-159 (2010)

7. Macedo, P., Camarinha-Matos, L.M.: Applying Causal Reasoning to Analyze Value Systems. In: Camarinha-Matos, L.M., Pereira, P., Ribeiro, L. (eds.) DoCEIS 2010. IFIP AICT, vol. 314, pp. 3-13. Springer, Heidelberg (2010)

8. Rokeach, M.: The nature of human values. Free Press, New York (1973)

9. Schwartz, S.H.: Universals in the content and structure of values: Theoretical advances and empirical tests in 20 countries. Advances in Experimental Social Psychology, 1-65 (1992)

10. Porter, M.: Competitive Advantage. The Free Press, New York (1985)

11. Alle, V.: Reconfiguring the Value Network. Journal of Business Strategy 21, 36-39 (2000)

12. Zineldin, M.A.: Towards an ecological collaborative relationship management A "coopetive" perspective. European Journal of Marketing 32, 1138-1164 (1998)

13. Abreu, A., Camarinha-Matos, L.M.: On the Role of Value Systems and Reciprocity in Collaborative Environments. In: Spring (ed.): Network-Centric Collaboration and Suporting Frameworks. IFIP, vol. 224, Springer, Boston (2006)

14. Camarinha-Matos, L.M., Afsarmanesh, H.: ECOLEAD: A holistic approach to creation and management of dynamic virtual organizations. In: Collaborative Networks and their Breeding Environments, pp. 3-16. Springer, Valencia (2005)

15. Kasanen, E., Lukka, K., Siitonen, A.: The Constructive Approach in Management Accounting Research. Journal of Management Accounting Research 5, 245-266 (1993)

16. March, S.T., Smith, G.F.: Design and natural science research on information technology. Decision Support Systems 15, 251-266 (1995) 